\title{
Host epithelial cell invasion by Campylobacter jejuni: trigger or zipper mechanism?
}

\section{Tadhg Ó Cróinín* and Steffen Backert*}

UCD School of Biomolecular and Biomedical Sciences, University College Dublin, Dublin, Ireland

\section{Edited by:}

D. Scott Merrell, Uniformed Services

University, USA

\section{Reviewed by:}

Hazel Marjory Mitchell, The University of New South Wales, Australia

Michael Konkel, Washington State

University, USA

*Correspondence:

Tadhg Ó Cróinín and Steffen Backert, UCD School of Biomolecular and

Biomedical Sciences, University

College Dublin, Belfield Campus,

Dublin-4, Ireland.

e-mail: tadhg.ocroinin@ucd.ie;

steffen.backert@ucd.ie
Campylobacter jejuni, a spiral-shaped Gram-negative pathogen, is a highly frequent cause of gastrointestinal foodborne illness in humans worldwide. Clinical outcome of $C$. jejuni infections ranges from mild to severe diarrheal disease, and some other complications including reactive arthritis and Guillain-Barré syndrome. This review article highlights various $C$. jejuni pathogenicity factors, host cell determinants, and proposed signaling mechanisms involved in human host cell invasion and their potential role in the development of $C$. jejuni-mediated disease. A model is presented which outlines the various important interactions of $C$. jejuni with the intestinal epithelium, and we discuss the pro's and con's for the "zipper" over the "trigger" mechanism of invasion. Future work should clarify the contradictory role of some previously identified factors, and should identify and characterize novel virulence determinants, which are crucial to provide fresh insights into the diversity of strategies employed by this pathogen to cause disease.

Keywords: molecular pathogenesis, cellular invasion, signaling, virulence

\section{INTRODUCTION}

Campylobacter jejuni and related species are commensals in many birds and domestic mammals, and have been recognized as being the most important cause of bacterial food poisoning worldwide. Infections with $C$. jejuni are the major cause of human bacterial gastroenteritis, and may be responsible for as many as $400-500$ million cases worldwide each year (Friedman et al., 2000). Disease outcomes vary from mild, non-inflammatory, self-limiting diarrhea to severe, inflammatory, bloody diarrhea lasting for several weeks, but $C$. jejuni is also associated with the development of the reactive arthritis and peripheral neuropathies, the Miller-Fisher and Guillain-Barrè syndromes in a minority of individuals (Young et al., 2007). The publication of numerous complete genome sequences of different $C$. jejuni strains has revealed an organism that displays a large degree of strain to strain variation. This natural heterogeneity has made studying the pathogenicity of this pathogen particularly challenging. However, significant progress has been made in recent years which has contributed to our understanding of the role of several key factors including the cytolethal distending toxin (Lara-Tejero and Galán, 2000; Ge et al., 2008) as well as glycosylation and molecular mimicry processes (Guerry and Szymanski, 2008; Nothaft and Szymanski, 2010). One of the key differences between infection of humans and chickens by $C$. jejuni is the apparently increased number of bacteria invading epithelial cells in the human host (Young et al., 2007). This suggests that both bacterial adherence to and entrance into epithelial cells may be critical steps that are essential for disease development. Thus, the identification of factors involved in these processes is the key for developing therapeutics to treat infections as well as enhancing our understanding of the pathogenesis.

There are two general strategies which the multitude of enteric bacterial pathogens use to enter host target cells. According to specific characteristics of the invasion process, we can distinguish between the classical "zipper"- and "trigger"-mechanisms, respectively (Cossart and Sansonetti, 2004). The "zipper"-mechanism is initiated by one or more bacterial surface proteins (commonly comprising adhesins and invasins) which bind to one or more specific host cell receptors followed by internalization, as reported for Yersinia or Listeria species (Figure 1A). On the other hand, the "trigger"-mechanism involves type-III and type-IV secretion systems (T3SSs and T4SSs) injecting bacterial proteins which often mimic or hijack specific host cell factors to trigger the bacterial uptake process, as described for Salmonella and Shigella (Figure 1B). Genome analyses revealed a notable absence of these classical pathogenicity factors in C. jejuni, making predictions very difficult. Since a suitable animal model system mimicking human infection is not available, a wide variety of in vitro cell culture models have been applied to identify the $C$. jejuni factors that play a role in adherence and invasion (Table 1). Unfortunately, the use of different $C$. jejuni strains and various cell models of infection led to substantial confusion and controversies in the literature. This review aims to summarize recent developments and to outline the experimental evidence for factors with proposed roles in adhesion and invasion. We discuss the pro's and con's of these findings in order to see whether C. jejuni may utilize a "zipper" or "trigger" mechanism of host cell invasion.

\section{BACTERIAL MOTILITY AND ROLE OF THE FLAGELLA}

Campylobacter jejuni is a highly motile organism with bipolar flagella which has been reported to be essential for colonization both in humans and animal models (Guerry, 2007). The organisms regulate motility through a complex chemotaxis system that allows to swim toward attractants and away from repellants (Lertsethtakarn et al., 2011). Early studies revealed that $C$. jejuni motility is required for invasion of epithelial cells in vitro as well as showing that increases in mucosal viscosity led to enhanced motility, 
A

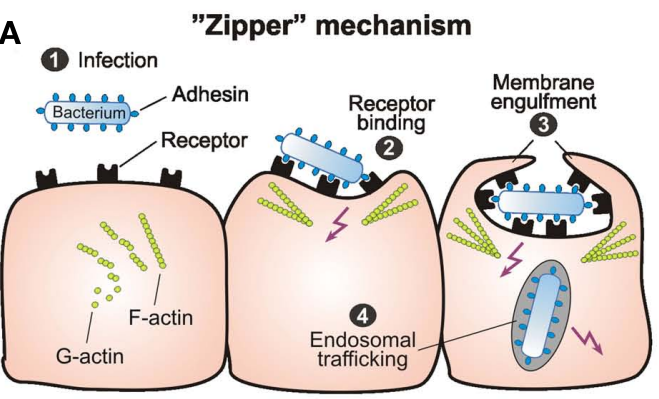

B

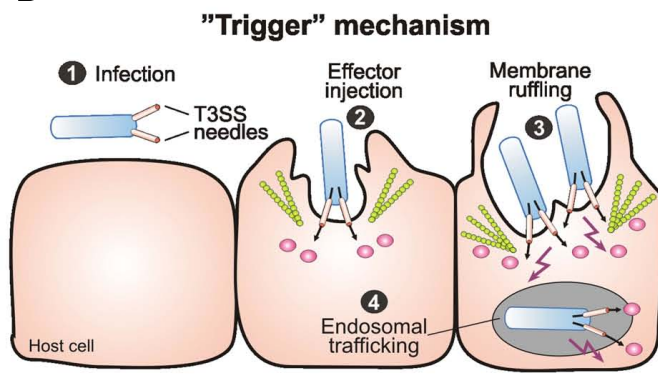

FIGURE 1 | Primary mechanisms of bacterial invasion into non-phagocytic host cells. Schematic representation of the two different routes of entry by intracellular bacterial pathogens. The pathogens induce their own uptake into target cells by subversion of host cell signaling pathways using the "zipper" and "trigger" invasion mechanism, respectively. (A) Bacterial gastrointestinal pathogens commonly colonize the gastric epithelium [step 1]. The "zipper" mechanism of invasion involves the high-affinity binding of bacterial surface adhesins to their cognate receptors on mammalian cells [step 2], which is required to initiate cytoskeleton-mediated zippering of the host cell plasma membrane around the bacterium [step 3]. Subsequently the bacterium is internalized into a vacuole. Some bacteria have developed strategies to survive within, or to escape from this compartment [step 4]. (B) The "trigger" mechanism is used by Shigella or Salmonella spp. which also colonize the intestinal epithelium [step 1]. These pathogens use sophisticated type-III or type-IV secretion system to inject various effector proteins into the host cell cytoplasm [step 2].
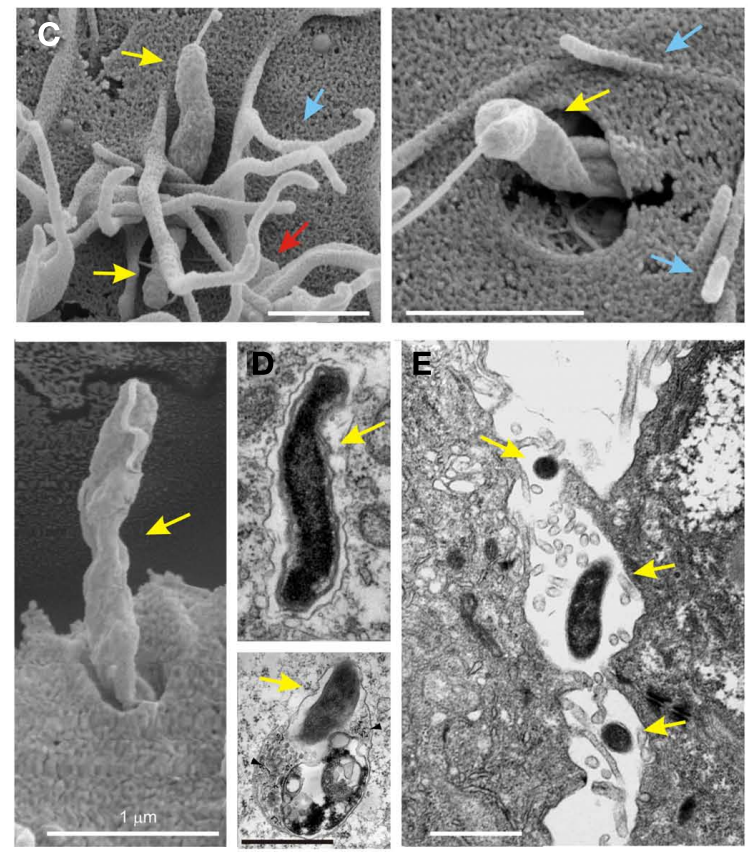

These factors manipulate a variety of signaling events including the activation of small Rho GTPases and cytoskeletal reorganization to induce membrane ruffling and subsequently bacterial uptake [step 3]. As a consequence of this signaling, the bacteria are internalized into a vacuole [step 4], followed by the induction of different signaling pathways for intracellular survival and trafficking. This figure was adapted from Tegtmeyer et al. (2011) with kind permission from Springer Publishing. (C) Scanning electron microscopy of $C$. jejuni 81-176 invasion. Invading bacteria (yellow arrows) were regularly associated with membrane ruffles (red arrows) and filopodia-like structures (blue arrows). This figure was adapted from Boehm et al. (2012). (D) Electron micrographs of $C$. jejuni-containing vacuoles (CCVs) that do not co-localize with BSA-gold (left) and CCVs that co-localize with BSA-Gold and resemble lysosomes (right, arrows) are shown. The two pictures were kindly provided by Dr. Galan (Watson and Galán, 2008). (E) The electron micrograph of translocating $C$. jejuni across polarized Caco-2 cells by the paracellular pathway was kindly provided by Dr. Konkel (Konkel et al., 1992b). adherence, and invasion (Szymanski et al., 1995). This apparent direct association between motility and invasion combined with the absence of an identifiable classical T3SS or T4SS led some groups to speculate that the flagellum could be also be used as a secretory device for invasion-associated effector molecules. In fact, the flagellum represents a T3SS by definition (Desvaux et al., 2006), and a series of papers have been published reporting the extracellular release of C. jejuni proteins in the presence of fetal calf serum (FCS) or upon host cell contact, which was abolished when crucial flagellar apparatus genes were inactivated. Additional support came from secretion experiments of Yersinia or C. jejuni virulence factors through their respective flagellar T3SS model system, suggesting that type-III protein secretion by the flagellum may be a general mechanism for the transport of proteins that influence bacterial-host interactions (Young et al., 1999; Christensen et al., 2009; Neal-McKinney et al., 2010).

The first identified secreted factor was the Campylobacter invasion antigen $\mathrm{B}(\mathrm{CiaB})$, a $73-\mathrm{kDa}$ protein with weak homology to T3SS effectors of other pathogens (Konkel et al., 1999). This paper showed that although ciaB mutants had no reduction in adherence to non-polarized INT-407 cells, a significant reduction of intracellular bacteria was observed. CiaB expression was also shown to be essential for the secretion of a whole family of other secreted Cia proteins that were induced in the presence of FCS (Rivera-Amill and Konkel, 1999). The CiaB protein was reported to be translocated into the cytoplasm of host cells, suggesting that it is a true effector molecule facilitating invasion (Konkel et al., 1999). A later study using a variety of mutants in flagellar subunits reported that the $\mathrm{CiaB}$ protein appeared to require at least one of the flagellar subunits for its secretion (Konkel et al., 2004). CiaB synthesis is reported to be induced by bile salts (Malik-Kale et al., 2008) and both synthesis and secretion can be induced by host cell components suggesting that the protein is under strict environmental regulation (Rivera-Amill et al., 2001). However, a very recent study has reported no significant reduction in invasion by a $c i a B$ mutant in the model strain 81-176 suggesting that further work is required to confirm the role played by this protein during infection (Novik et al., 2010). Since the discovery of CiaB we have 
Table 1 | Bacterial factors and proposed roles in $C$. jejuni infection.

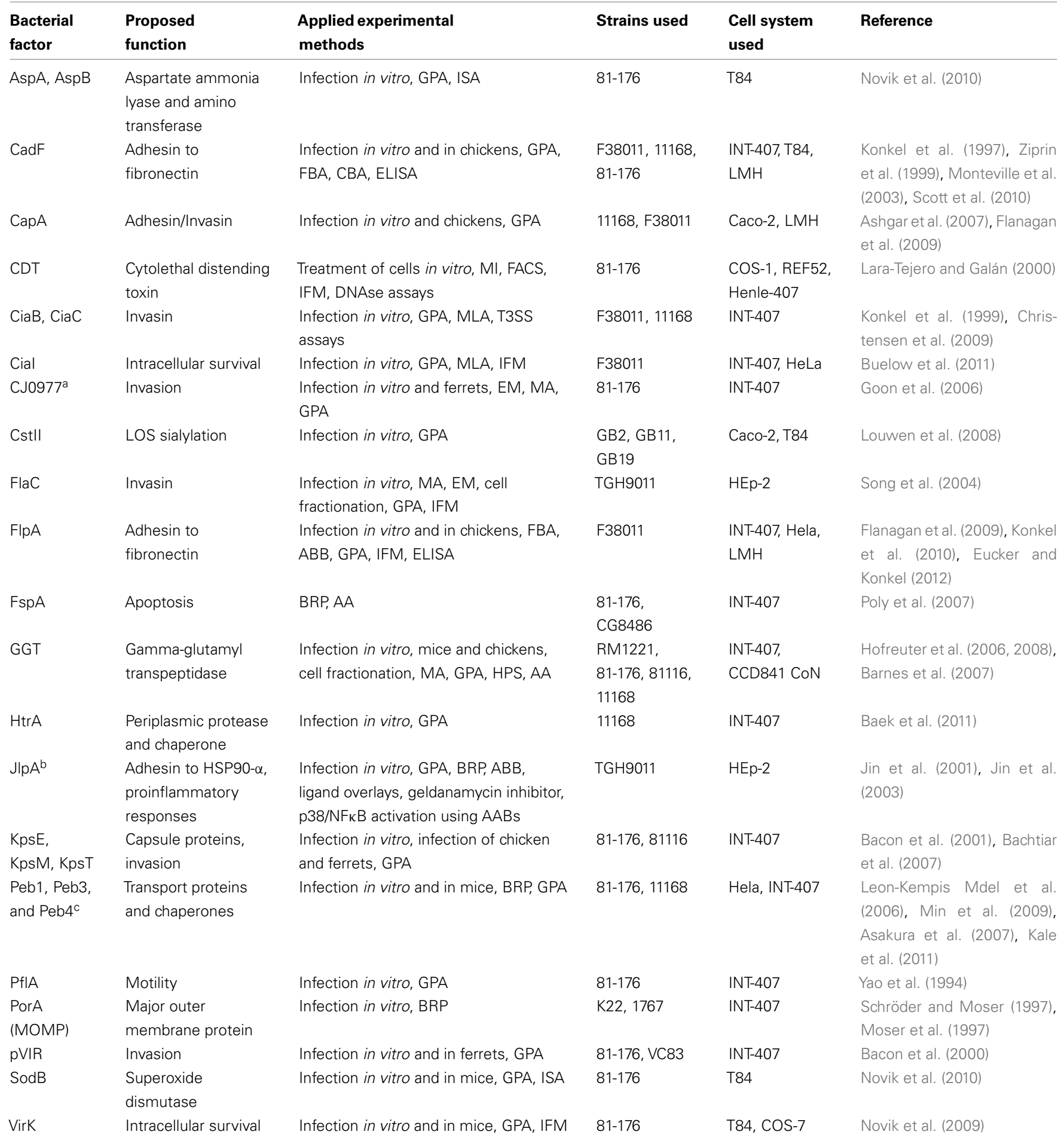

$A A$, apoptosis assay; $A B$, antibody; $A A B$, activation-specific antibodies; $A B B$, antibody blocking; BRP, binding assays using recombinant or purified protein; $C B A$, competitive binding assay; EM, electron microscopy; FACS, fluorescence-activated cell sorting; FBA, fibronectin binding assay; GPA, gentamicin protection assay; HPS, hydrogen peroxide susceptibility test; IFM, immunofluorescence microscopy; ISA, intracellular survival assay; MI, microinjection of proteins; MA, motility assay on agar; MLA, ${ }^{35 S}$-methionine labeling assay; pVIR, mobilizable plasmid in some strains; T3SS assays, translocation assay using the Yersinia flagellar type-III secretion apparatus.

${ }^{a}$ Another report indicated that the Cj0097 mutant has a deficiency in motility in liquid broth (Novik et al., 2010).

${ }^{b}$ Identified as an adhesin in strain TGH9011, but no effect observed with jlpA mutants in either 11168 or 81-176 strains (van Alphen et al., 2008; Novik et al., 2010).

'These structural studies along with other assays suggest primary roles in protein transport. Originally, the Peb's were identified as putative adhesins (Pei et al., 1991). 
seen the emergence of other potential Cia proteins which have been speculated to be important virulence factors. CiaC is such an example and reported to be essential for maximal invasion of INT-407 cells (Christensen et al., 2009; Eucker and Konkel, 2012). CiaI has also been recently identified as a protein secreted through the flagellar transport system, and appears to play a role in intracellular survival (Buelow et al., 2011). Another protein which has been postulated by one group to be secreted through the flagellum is FlaC. This protein has strong homology with the flagellin subunit proteins FlaA and $\mathrm{FlaB}$, and has been shown to play a role in invasion using the HEp-2 in vitro cell model (Song et al., 2004). The FspA protein which has been shown to induce apoptosis in INT-407 cells has also been reported to be secreted through the flagellum (Poly et al., 2007).

\section{CadF AND FIpA FIBRONECTIN BINDING PROTEINS}

Perhaps the most well characterized $C$. jejuni factor interacting with host cells is the CadF protein. CadF was first identified as a $37-\mathrm{kDa}$ protein that bound the extracellular matrix (ECM) protein fibronectin, in either immobilized or soluble form (Konkel et al., 1997). The sequence of the cadF gene product revealed a protein with homology to an adhesin from Pseudomonas fluorescens. In the same year another group confirmed the observation that recombinant CadF bound to fibronectin as well as reporting that the protein could bind to membrane fractions of INT-407 cells in vitro (Moser et al., 1997). A later study revealed the importance of CadF for colonization, as cadF mutants were unable to infect chickens (Ziprin et al., 1999). Using the polarized cell line T84 it was reported that $C$. jejuni crossed the epithelial layer between neighboring cells (paracellular route) and invasion might occur through the basolateral but not apical surface (Monteville and Konkel, 2002). This study also revealed that CadF expression was required for maximal T84 cell binding. A later study identified the fibronectin binding domain in CadF as four surface-exposed amino acids at position 134-137 (Konkel et al., 2005). Mutations in these residues significantly reduced binding to fibronectin and INT-407 cells while peptides containing this putative fibronectin binding site exhibited blocking capacity for binding. Interestingly, Krause-Gruszczynska et al. (2007a) have reported that a 39-bp insertion in the $c a d F$ gene of $C$. coli strains leads to a larger protein and that these strains bind and invade INT-407 cells less efficiently than C. jejuni. In C. jejuni, CadF expression has been reported to be downregulated in response to human mucin Muc2, suggesting that levels of expression of the protein may vary during the infection cycle (Tu et al., 2008). Interestingly, most strains of C. jejuni exhibit two bands in Western blots using anti-CadF antibodies, suggesting that distinct forms of the protein may exist. A recent study using mass spectroscopy proposed that CadF may undergo post-translational processing steps, which result in certain cases in the removal of the immunogenic epitope but retention of the fibronectin binding site (Scott et al., 2010). The exact role that these different CadF forms play during infection is not yet fully understood.

Recently, a second potential fibronectin binding protein has been identified in C. jejuni called FlpA. FlpA was first described as being a protein which played a role in adherence to chicken epithelial cells as well as playing a significant role in colonization of chickens (Flanagan et al., 2009). The protein was later described as being capable of binding fibronectin and that $f l p A$ mutants showed a significant decrease in binding to INT-407 cells as compared to the wild-type strain (Konkel et al., 2010). However, neither CadF nor FlpA or any Cia protein were found in a global screen for invasion-related genes in strain 81-176 (Novik et al., 2010). A recent study has proposed that $\mathrm{CadF}$ and FlpA may act together to target fibronectin for bacterial binding and subsequent invasion by C. jejuni (Eucker and Konkel, 2012). This indicates that certain additive effects of genes involved in cell adhesion and invasion may play a role. However, inhibitor studies using chloramphenicol showed that bacterial protein synthesis is required for maximal C. jejuni invasion (Konkel and Cieplak, 1992; Oelschlaeger et al., 1993). Chloramphenicol retards the expression of Cia proteins but not CadF or FlpA (Christensen et al., 2009; Eucker and Konkel, 2012), suggesting that constitutive expression of these adhesins alone is not sufficient for the bacterial uptake process.

\section{ROLE OF JIpA}

JlpA is a $42-\mathrm{kDa}$ lipoprotein which can be $N$-linked glycosylated at two residues (Scott et al., 2009). This surface-exposed lipoprotein has also been implicated as an important adhesin for $C$. jejuni. An initial study in 2001 revealed that $j l p A$ mutants exhibit a decreased ability to bind to HEp-2 cells (Jin et al., 2001). It was also reported in this study that binding of the wild-type strain could be inhibited by either pre-incubation with recombinant JlpA protein or antibodies raised against JlpA. A later study revealed that recombinant JlpA bound to HEp-2 cells and that the corresponding receptor appeared to be a $90-\mathrm{kDa}$ protein, which was identified as a heat shock protein, HSP90- $\alpha$ (Jin et al., 2003). Furthermore, the $j l p A$ gene has been shown to be upregulated in response to human mucin along with other $C$. jejuni genes suggesting the protein may play a key role in pathogenicity (Tu et al., 2008). However, two other studies have been unable to show a role for JlpA in adherence of C. jejuni. One study, using T84 cells, revealed a minimal reduction in invasion with a $j l p A$ mutant when compared to the wild-type strain (Novik et al., 2010), while the other study which used a chicken epithelial cell line revealed no reduction in invasion of a jlpA mutant (Flanagan et al., 2009). This study also reported no defect in colonization of broiler chickens by a jlpA mutant. Whether these conflicting results are due to strain variation or differences in experimental approaches is not yet clear (Table 1).

\section{ROLE OF Peb PROTEINS}

One group of $C$. jejuni surface molecules that were originally implicated as being involved in adhesion to epithelial cells are the Peb proteins. These proteins were first described as "CBF proteins," which were observed to range from between 26 to $30-\mathrm{kDa}$ and were shown to be present in bacterial outer membrane fractions which bound to Hela cells (Fauchere et al., 1989). These proteins were originally described as being major immunogenic antigens of C. jejuni (Pei et al., 1991). Peb1 (originally called CBF1) was first described as playing a key role in the adherence to epithelial cells (Fauchere et al., 1989). Later studies revealed that Peb1 was surface-exposed and showed that purified Peb1 bound to HeLa cell membranes in vitro, and that co-incubation with anti-Peb1 antibodies significantly reduced adherence of $C$. jejuni to intact HeLa 
cells (Kervella et al., 1993). This role in adherence was confirmed when a peb1 mutant was shown to display a clear reduction in adherence to HeLa cells, invasion of INT-407 cells as well as a significant reduction in its ability to colonize the mouse intestine as compared to the wild-type strain (Pei et al., 1998). However, later studies reported that a peb1 mutant exhibited a minimal reduction in invasion of T84 cells or adherence to chicken epithelial cells, suggesting that the importance of Pebl in adherence or invasion may vary depending on the assay and cell system used (Flanagan et al., 2009; Novik et al., 2010).

When the gene encoding Peb1 was originally identified and sequenced, it revealed some homology to proteins involved in amino acid transport systems in other bacteria (Pei and Blaser, 1993). A more recent study has confirmed that Peb1 binds aspartate and glutamic acid, and suggested that the protein was predominantly found in the periplasm and not in the inner or outer membranes (Leon-Kempis Mdel et al., 2006). These studies may implicate that the primary role of the Peb1 protein may be the utilization of certain amino acids. The recently published crystal structure of Peb1 has identified key domains which may indeed play a role in binding amino acids and may provide a basis for furthering our understanding of how this protein carries out this function and how this affects the ability of the organism to adhere to or invade epithelial cells (Muller et al., 2007).

A similar dual role has also been suggested for other reported Peb proteins (Table 1). Like Peb1, Peb4 had been implicated as a potential adhesin of C. jejuni (Kervella et al., 1993; Asakura et al., 2007). When the nucleotide sequence of Peb4 was first deduced it revealed a gene with homology to factors involved in protein export (Burucoa et al., 1995). This role in protein export has since been confirmed by a study showing profound effects on the outer membrane profile in a peb4 mutant including a reduction in CadF protein levels (Rathbun and Thompson, 2009). The recently published crystal structure of Peb4 has confirmed that the protein appears to be a chaperone and may thus play a key role in exporting proteins to the outer membrane and that this may explain its role in adherence (Kale et al., 2011). A later study revealed that Peb3 may be a transport protein involved in the utilization of 3phosphoglycerate (Min et al., 2009). These reports highlight the difficulty in identifying the specific mechanism of action of these proposed "adhesins" and further studies are required to discover what exact role the Peb proteins play in $C$. jejuni adherence or invasion.

\section{OTHER PROPOSED FACTORS INVOLVED IN ADHESION}

Several other genes have also been reported as playing a role in either adherence or invasion by C. jejuni. The CapA (Campylobacter protein A) protein was initially identified as an autotransporter protein and a capA mutant displayed reduced adherence to and invasion of Caco-2 cells as well as an inability to colonize chickens (Ashgar et al., 2007). A later study confirmed the role of this protein as a putative adhesin or invasin using chicken epithelial cells but revealed no colonization defect in chickens (Flanagan et al., 2009). About $40 \%$ of human isolates and $39 \%$ of chicken isolates in this study lack the capA gene, which can explain the reduced bacterial binding to LMH cells as compared to capA expressing control strains. Two other proteins, KpsE and KpsM, which are involved in capsule production have also been implicated as playing a role in invasion. In vivo experiments using $k p s E$ and $k p s M$ mutants in the ferret model have indicated the role played by the capsule in colonization (Bacon et al., 2001; Bachtiar et al., 2007). Another proposed adhesin is Cj0977 (Goon et al., 2006), but later studies have shown that reduced binding maybe due to a deficiency in motility in liquid broth (Novik et al., 2010), although the mutants were motile on soft agar plates (Goon et al., 2006). Furthermore, another study has revealed the role played by lipooligosaccharide (LOS) sialylation as mutants in the cstII gene showed reduced ability to enter epithelial cells (Louwen et al., 2008). Other proteins recently identified as affecting adherence and invasion levels also include the chaperone and serine protease HtrA (Baek et al., 2011) and VirK (Novik et al., 2009). Baek et al. showed that the chaperone activity of HtrA in the periplasm may affect proper folding of adhesins involved in host cell binding, whereas Novik et al. pointed out that the reduction of intracellular bacteria observed in the gentamycin protection assay (GPA) with a virK mutant may be primarily due to a $\sim 100$-fold increase in susceptibility to certain antimicrobial peptides. Finally, although some genes have been identified on the pVIR plasmid in strain 81-176 to play a role in invasion, these genes seem to be strain-specific as they are only present in a very small subset $(\sim 10 \%)$ of $C$. jejuni isolates (Bacon et al., 2000, 2002).

\section{THE CELLULAR INVASION PROCESS}

Early reports which investigated intestinal biopsies from human patients indicated that $C$. jejuni is able to enter gut tissue cells in vivo (van Spreeuwel et al., 1985). Numerous studies have then shown that $C$. jejuni can invade and survive within a number of cultured cell lines in vitro (Table 2). Various C. jejuni factors permitting motility, glycosylation, capsular synthesis, and adherence have been implicated in the invasion process (Grant et al., 1993; Yao et al., 1994; Pei et al., 1998; Bacon et al., 2001; Konkel et al., 2001; Szymanski et al., 2002). Very commonly, C. jejuni with introduced mutations in these genes exhibited various degrees of deficiency in binding to and entering human target cells, or in colonizing certain animal models including chicken and mice (Hendrixson and DiRita, 2004; Kakuda and DiRita, 2006; Watson and Galán, 2008; Novik et al., 2010). A common laboratory method to monitor adherence and invasion is GPA, but also immunofluorescence and electron microscopy (EM) approaches have been utilized in some but not all studies (Table 2). However, it is not yet clear which mechanism of invasion, "zipper" or "trigger," is used by $C$. jejuni. High resolution EM investigation of infected non-polarized INT-407 and other cell lines indicated that $C$. jejuni induces membrane ruffling in a contact-dependent manner followed by host cell entry, first with its flagellar tip followed by the opposite flagellar end (Krause-Gruszczynska et al., 2007b, 2011; Boehm et al., 2012), surprisingly sharing some features of both "zipper"- and "trigger"-mechanisms (Figure 1C).

\section{PUTATIVE HOST CELL RECEPTORS AND KINASES INVOLVED IN THE INVASION PROCESS}

Lipid rafts are specific microdomains of plasma membrane of eukaryotic host cells which are enriched in cholesterol and sphingolipids, and favor the interactions of receptor molecules and 
Table $2 \mid$ Host factors and proposed roles in $C$. jejuni infections.

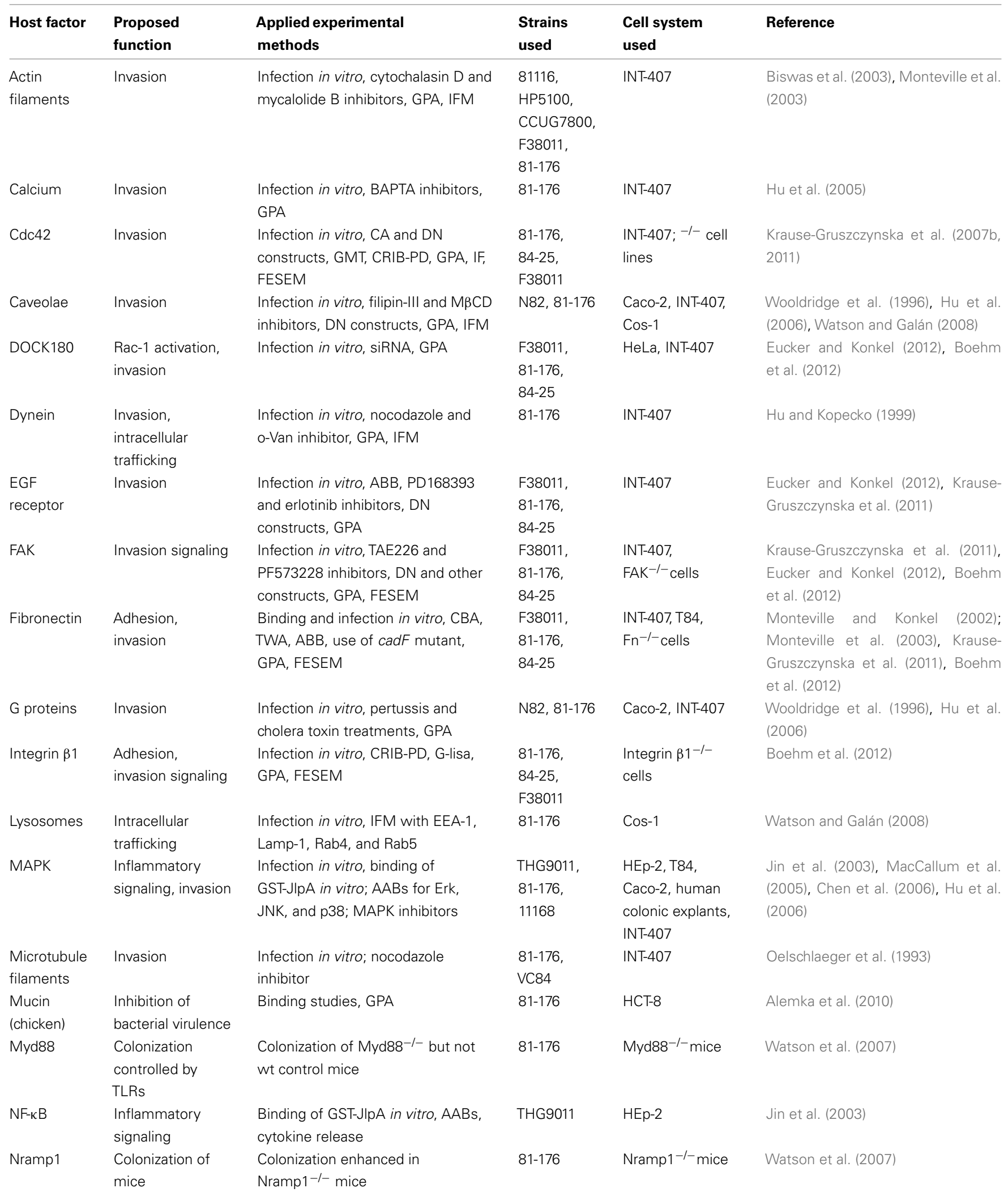


Table 2 | Continued

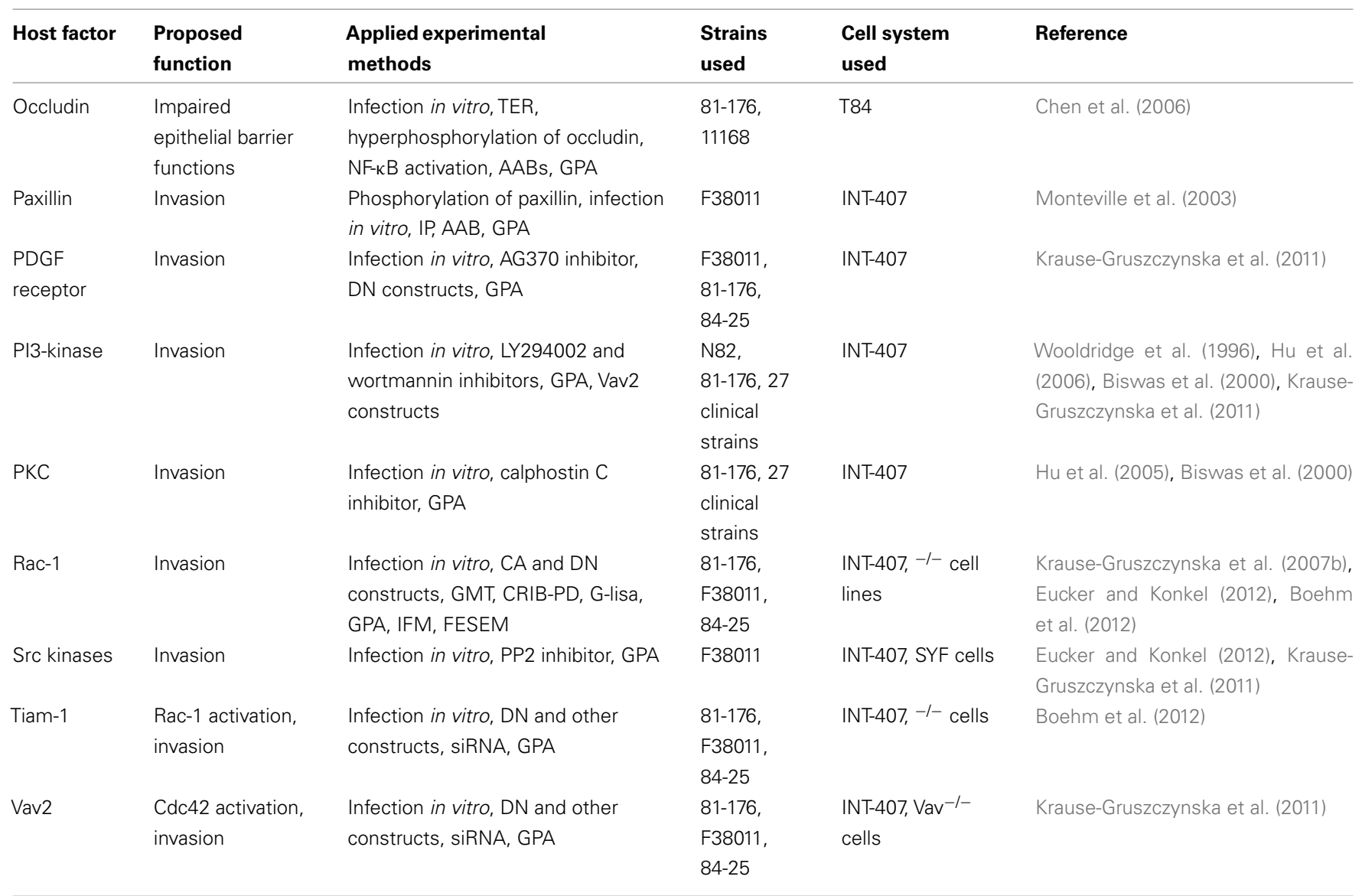

$A B$, antibody; $A A B$, activation-specific antibody; $A B B$, antibody blocking; $C B A$, competitive binding assay; $M B C D$, methyl-beta cyclodextrin; $C A$ constructs, constitutiveactive constructs; DN constructs, dominant-negative constructs; IP, immunoprecipitation; CRIB-PD, pull-down experiments to quantify GTPase-GTP levels; EEA-1, early endosomal marker 1; FAK, focal adhesion kinase; FESEM, field emission scanning electron microscopy; Fn, Fibronectin, G-lisa, ELISA-based GTPase-GTP quantification system; GPA, gentamicin protection assay, GST-JIpA, glutathione-S- transferase-tagged JIpA; GMT, GTPase-modifying toxins such as toxin B or CNF, which either inhibit or activate GTPases; IFM, immunofluorescence microscopy; IP, immunoprecipitation; MAPK, mitogen-activated protein kinases; MyD88, myeloid differentiation factor 88; o-Van, ortho-vanadate inhibitor; PKC, protein kinase C; SYF, Src ${ }^{-1}$, Yes ${ }^{-1}$, Fyn ${ }^{-1-}$ triple knockout cells; TER, transepithelial resistance; TWA, transwell assays with polarized cells; Vav2, guanine exchange factor of the Vav family; wt, wild-type; ${ }^{--}$, knockout cells.

the regulation of downstream signaling pathways. Pharmacological inhibitor studies using the lipid raft-disrupting compounds filipin-III or $\mathrm{M} \beta \mathrm{CD}$ as well as certain toxins have indicated that host heterotrimeric $\mathrm{G}$ proteins and caveolae may be involved in epithelial cell entry of C. jejuni (Wooldridge et al., 1996; Hu et al., 2006; Watson and Galán, 2008). Expression of dominant-negative mutants of caveolin-1 but not dynaminII significantly decreased C. jejuni internalization (Watson and Galán, 2008), suggesting that caveolin-1 in caveolae structures may play a role in the uptake process (Figure 2). Interestingly, $C$. jejuni is severely hampered in its ability to invade cell lines derived from fibronectin ${ }^{-/-}$, integrin- $\beta 1^{-1-}$, focal adhesion kinase $(\mathrm{FAK})^{-1-}$, and $\mathrm{Src}^{-1-} / \mathrm{Yes}^{-1-} / \mathrm{Fyn}^{-1-}$ (SYF) triple knockout mice using EM and/or GPA, but can efficiently enter wild-type control cells (Krause-Gruszczynska et al., 2011; Boehm et al., 2012). Infection of integrin- $\beta 1^{-1-}$ knockout cells stably expressing integrin- $\beta 1$ point mutants with well-known defects in extracellular fibronectin fibril formation or intracellular FAK signaling also exhibited severe deficiencies in $C$. jejuni invasion (Krause-Gruszczynska et al., 2011). Novel data also showed that FAK and certain receptor protein tyrosine kinases such as EGF receptor (EGFR) and platelet derived growth factor receptor (PDGFR) are activated by $C$. jejuni and involved in the uptake process (Krause-Gruszczynska et al., 2011; Boehm et al., 2012; Eucker and Konkel, 2012). Another focal adhesion signaling molecule, paxillin, also exhibited increased levels of tyrosine phosphorylation upon C. jejuni infection, which was not seen during infection with mutants of the fibronectin binding protein CadF (Monteville et al., 2003). These data collectively suggest that the $\mathrm{CadF} \rightarrow$ fibronectin $\rightarrow$ integrin- $\beta 1 \rightarrow$ FAK $\rightarrow$ paxillin pathway is another major signaling cascade involved in C. jejuni-mediated host cell entry (Figure 2). In addition, inhibitor studies combined with GPA have suggested that phosphatidylinositol 3-kinase (PI3-kinase), protein kinase $\mathrm{C}$ (PKC), and mitogen-activated protein kinases (MAPKs) are involved in events controlling C. jejuni internalization (Wooldridge et al., 1996; Biswas et al., 2000; Hu 


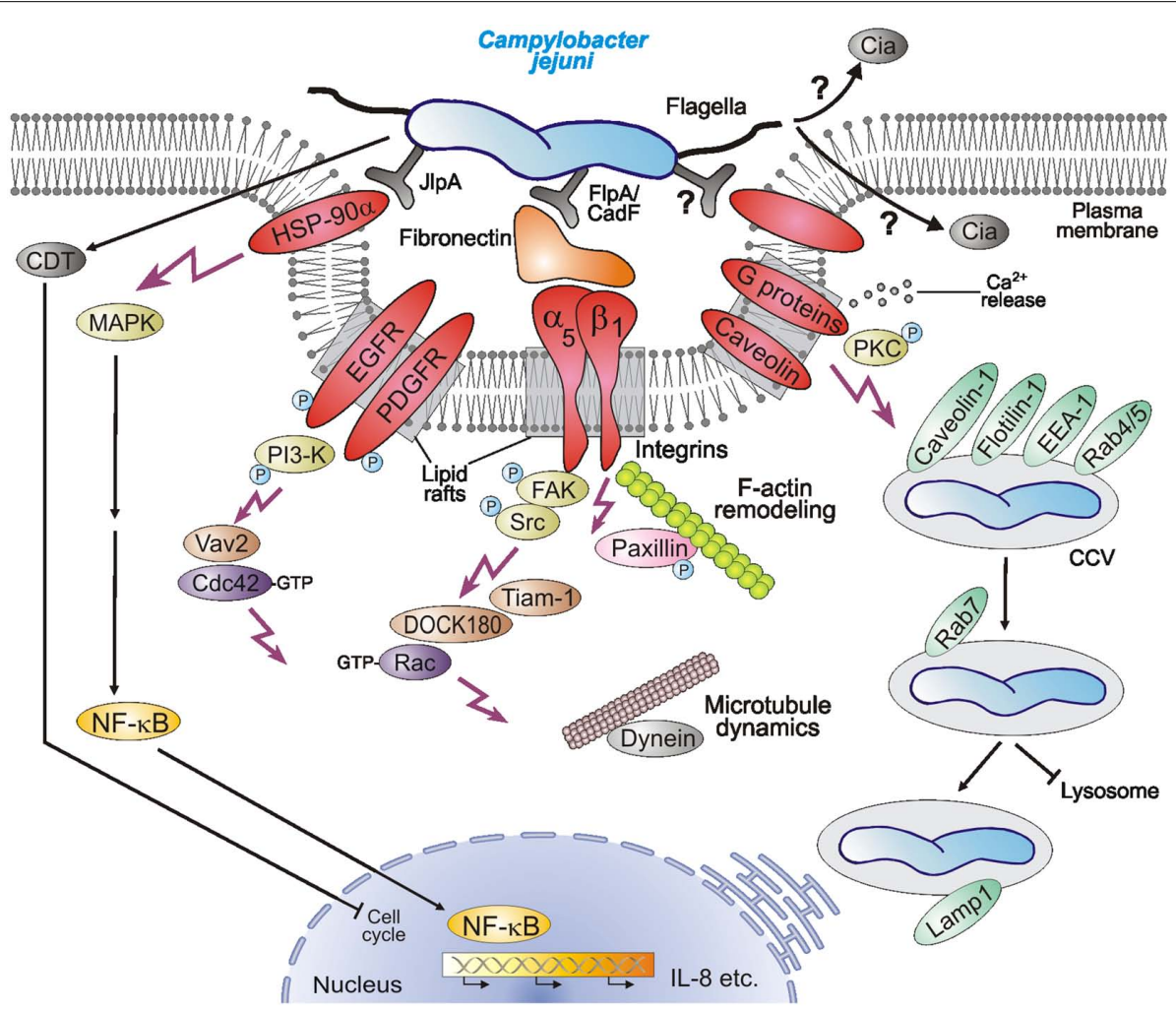

\begin{tabular}{|llll|}
\hline Bacterial factors & $\square$ Kinases & $\square$ F-actin & $\square$ Transcription factors \\
$\square$ Receptors & $\square$ Scaffold proteins & $\square$ Tubulins & GTPases \\
$\square$ ECM proteins & $\square$ Endocytic markers & $\square$ Motor proteins & $\square$ GEFs \\
\hline
\end{tabular}

FIGURE 2 | Hypothetical model for $C$. jejuni-induced signaling events leading to bacterial invasion and establishing infections. $C$. jejuni adheres to host cells via numerous reported and unknown factors. Several indicated host cell receptors have been proposed to play a role in the uptake of the bacteria. This potentially causes localized F-actin and/or microtubule rearrangements at the site of $C$. jejuni entry, resulting in engulfment and bacterial uptake. Several indicated host cell signaling molecules and pathways including the intracellular survival in Campylobacter-containing vacuoles (CCVs) have been reported in in vitro infection models and may play a role during pathogenesis in vivo. For more details, see tables and text. et al., 2006). Other inhibitor-based work has also shown that $\mathrm{Ca}^{2+}$ release from host intracellular stores is essential for efficient $C$. jejuni recovery by GPA (Hu et al., 2005). However, whether most of the latter factors are directly involved in the bacterial entry step or trafficking linked to intracellular bacterial survival is not yet clear.

\section{FUNCTION OF GEFs AND SMALL Rho GTPases IN C. jejuni INVASION}

The Rho family of small GTPases, including Rac-1, Cdc42, and RhoA, are small GTP-binding proteins that serve as guanine nucleotide-regulated switches which transmit external stimuli to modulate different normal cellular functions as well as invasion of multiple bacterial pathogens (Cossart and Sansonetti, 2004). The internalization of C. jejuni into INT-407 cells is accompanied by a time-dependent activation of both Rac-1 and Cdc42 (Krause-Gruszczynska et al., 2007b, 2011; Boehm et al., 2012; Eucker and Konkel, 2012). Using specific GTPase-modifying toxins, inhibitors, and GTPase expression constructs it was shown by immunofluorescence, GPA, and other studies that Rac-1 and Cdc42, but not RhoA, are involved in C. jejuni invasion (KrauseGruszczynska et al., 2007b). Interestingly, the activation of these GTPases and induction of membrane ruffling by $C$. jejuni was severely inhibited in infected fibronectin ${ }^{-l-}$, integrin $-\beta 1^{-1-}$, $\mathrm{FAK}^{-1-}$, and $\mathrm{SYF}^{-1-}$ knockout cell lines, although the bacteria had intact flagella and bound to their cell surface (KrauseGruszczynska et al., 2011; Boehm et al., 2012). Maximal GTPaseGTP levels induced by $C$. jejuni also involve EGFR, PDGFR, FAK, Src, and PI3-kinase activities as supported by inhibitor studies, and the bacterial fibronectin binding protein CadF as well as the flagellum and one secreted Campylobacter invasion antigen, CiaC (Krause-Gruszczynska et al., 2007b, 2011; Eucker and Konkel, 2012). Immunofluorescence data also indicated that CiaC is essential for recruitment of Rac-1 to the site of $C$. jejuni adherence (Eucker and Konkel, 2012). The exact role of CiaC, however, is not yet clear, but it would appear that it does not encode a guanine exchange factor (GEF) for activating Rac-1. CiaC shares no sequence homology with the well-known GEFs from Shigella 
flexneri or Salmonella enterica, which are directly injected into the host cell by a T3SS and known to induce extensive membrane ruffling by the "trigger" mechanism (Cossart and Sansonetti, 2004). In agreement with these observations, two host cell GEFs (DOCK180 and Tiam-1) were identified to trigger Rac-1 activity downstream of FAK based on small inhibitory RNA (siRNA) knockdown, inhibitors, and the use of $\mathrm{FAK}^{-/-}$knockout cell experiments (Boehm et al., 2012; Eucker and Konkel, 2012), while another GEF (Vav2) is downstream of FAK, EGFR, PDGFR, and PI3-kinase to trigger Cdc42 GTPase activity (Krause-Gruszczynska et al., 2011). Collectively, these results suggest that $C$. jejuni actively triggers signaling to stimulate their own uptake by host target cells using a unique mechanism and the activation of the Rho GTPase members Rac- 1 and Cdc42 plays a crucial role in this entry process (Figures 1C and 2).

\section{ROLE OF MICROFILAMENTS VERSUS MICROTUBULES DURING INVASION}

Microfilaments (MFs) and microtubules (MTs), which are composed of actin or tubulin subunits, respectively, play an important role in cell architecture and other basic cellular processes. Using inhibitor and GPA studies, C. jejuni internalization has been variously reported to require MTs (Oelschlaeger et al., 1993; Hu and Kopecko, 2008), MFs (De Melo et al., 1989; Konkel and Joens, 1989), both MTs and MFs (Oelschlaeger et al., 1993; Biswas et al., 2003; Monteville et al., 2003), or neither MTs or MFs (Russell and Blake, 1994). Other studies investigated the co-localization of infecting C. jejuni with MTs and the molecular motor protein dynein (Hu and Kopecko, 1999), but also with MFs (Konkel et al., 1992a; Rivera-Amill et al., 2001; Krause-Gruszczynska et al., 2007b). This available data, although not sufficient to allow definitive conclusions, suggest that different $C$. jejuni strains may prefer MT-dependent or MF-dependent pathways for host invasion, while others may depend on both MTs and MFs during invasion. Remarkably, after about 20 years of research, the C. jejunimediated triggers which result in MT and/or MF rearrangements to facilitate bacterial uptake are still not clear. It will therefore be important to investigate how activated caveolae, FAK, EGFR, PDGFR, PI3-kinase, Rac-1, Cdc42, or other host factors could potentially stimulate MFs and/or MTs dynamics to mediate the $C$. jejuni entry process.

\section{INTRACELLULAR TRAFFICKING AND SURVIVAL OF C. jejuni}

Various intracellular pathogens utilize a variety of strategies to live and replicate within host cells. GPA and EM studies have shown that $C$. jejuni can survive for extended periods of time in several cell lines and tissues (Table 2). Following entry into intestinal epithelial cells, C. jejuni appears to localize in a specific compartment in the cytoplasm, which seems to be distinct from the lysosomes (Watson and Galán, 2008). It was found that the C. jejuni-containing vacuole (CCV) deviates from the canonical endocytic pathway immediately after host cell entry, thus avoiding delivery into lysosomes (Figure 1D). The CCV appears to interact with early endosomal compartments because it associates with early endosomal marker protein EEA-1 and two trafficking GTPases, Rab4, and Rab5 (Figure 2, right). However, this interaction seems only transient and does not progress inside the canonical endocytic pathway (Watson and Galán, 2008). The CCV can be also stained with Lamp-1, a late endosomal marker, although this compartment appears to be unique and clearly distinct from lysosomes (Figure 2). CCVs were not stainable with the lysosomal marker protein cathepsin B and it is also not accessible to certain endocytic tracers (Watson and Galán, 2008). Taken together, the acquisition of Lamp-1 occurring very early during maturation of CCVs, appears to proceed by an unusual pathway not requiring the GTPases Rab5 or Rab7, although recruited to the CCV. More studies are required to elucidate in more detail the mechanism by which C. jejuni modulates intracellular trafficking and survival.

The subset of C. jejuni genes which are important for intracellular trafficking and survival are widely unknown, but a couple of potential factors are emerging. One of these factors is CiaI, a reported secreted protein (Buelow et al., 2011). A ciaI mutant was impaired in intracellular survival by GPA. Immunofluorescence examination indicated that the ciaI mutant more frequently colocalized with Cathepsin D in the CCVs as compared to wild-type bacteria, and is probably killed in these compartments. In another recent study, insertional mutation of three novel genes named $\operatorname{asp} A, \operatorname{asp} B$, and $\operatorname{sod} B$ also exhibited clear defects in intracellular recovery by GPA (Novik et al., 2010). Further characterization of these mutants revealed that the reduction in recovered bacteria was due to a combined defect in adhesion and impaired intracellular viability (SodB) or undetermined effects on bacterial physiology (AspA and AspB). These studies highlight the importance of the use of multiple assays to identify and characterize genes which play potential roles in C. jejuni adherence and invasion.

\section{URGENT PROBLEMS TO BE SOLVED}

Campylobacter jejuni is a remarkable foodborne microbe, but by comparison to other well-known enteric pathogens, we know very little about the bacterial and host factors involved in establishing infection and triggering disease. This dilemma is in part due to the clear absence of classical bacterial adhesins, toxins, or typical T3SSs or T4SSs in the sequenced C. jejuni genomes. The other enormous handicap is the large amount of highly conflicting data in the literature. For almost every reported factor proposed to be involved in a given host response, there is at least one other study showing the opposite. It is possible that the reported results depend on the specific strains used, how the bacteria were grown, but also on differences in the experimental conditions and applied methodology (Tables 1 and 2). In addition, many studies using single mutants lack genetic complementation of the corresponding wild-type gene, which although technically very difficult in $C$. jejuni, would be very useful to restore the phenotypes reported for many of the aforementioned pathogenicity factors. Furthermore, one must be very careful when using methods such as GPA as an accurate measurement of bacterial invasion. GPA determines the number of viable CFU protected from gentamicin, and thus represents a direct measurement of intracellular surviving bacteria, rather than a direct measure of the invasion process itself? Some studies have identified factors which appear to play a direct role in invasion when studied using GPA, but when studied using other methods are actually revealed to have an indirect role. These include AspA and AspB whose primary role was shown to be in 
the production of fumarate but when mutated displayed a reduction in invasion by the GPA assay (Novik et al., 2010). However, this effect could be reversed by the addition of fumarate showing that this reduction was due to physiological effects rather than these proteins functioning as adhesins or invasins directly (Novik et al., 2010). Studies such as these highlight how important it is to use a variety of experimental approaches to identify and study any factors found to play a role in host cell interactions. The same arguments apply for certain studies using pharmacological inhibitors. Besides such problems as the lack of controls, it should be asked if these inhibitors or their solvents alone have specific activities on the host or bacteria over time and, if properly performed, does a given compound really inhibit the entry process itself or does it interfere with bacterial survival in the CCVs? GPA certainly does not discriminate between these different possibilities either. Thus, in future, more direct methods such as novel microscopic technologies are necessary to investigate in detail the involvement of certain host factors in bacterial engulfment and uptake, but also in intracellular survival processes.

Although several of the discussed GPA studies have identified certain C. jejuni gene mutants exhibiting severe defects in entering or surviving in cells, there is no direct evidence yet that any of the identified gene products can directly trigger invasion (Tables 1 and 2). For example, it is still controversial if the role of the flagellum during invasion is restricted to bacterial motility or secretion of bacterial Cia proteins into the medium or even injection into the host cell. This model of Cia protein secretion through the flagellum is very tempting and would support the idea that Campylobacter uses a "trigger mechanism" of invasion involving the secretion of effector proteins directly into the cell to induce their uptake, similar to Salmonella and Shigella. Some electron microscopic evidence exists that would support this model (Figure 1C), but it should be noted that a recent study has suggested that CiaB plays a minimal or no role in invasion (Novik et al., 2010). Thus, much more work is required to confirm the role of the flagellum as a secretion system for effector proteins involved in invasion.

Confusion also exists as to the exact role played by some of the previously proposed adhesins. Proteins such as JlpA have been described by some authors as being an important adhesin (Jin et al., 2001), whereas other groups have been unable to show any significant decrease in invasion in a jlpA mutant (Novik et al., 2010). Furthermore, factors such as the PEB proteins which were originally described as adhesins (Pei et al., 1991) now appear to primarily have roles as transporters (Leon-Kempis Mdel et al., 2006) or as chaperones (Kale et al., 2011), suggesting that they may not directly interact with the host cell but play a more indirect role. One protein that is very well characterized and appears to clearly play a role in adherence to host epithelial cells is CadF (Monteville et al., 2003). This protein along with the recently described FlpA protein

\section{REFERENCES}

Alemka, A., Whelan, S., Gough, R., Clyne, M., Gallagher, M. E., Carrington, S. D., and Bourke, B. (2010). Purified chicken intestinal mucin attenuates Campylobacter jejuni pathogenicity 898-903.

Asakura, M., Yamasaki, M., Yamamoto, S., and Igimi, S. (2007) Deletion of peb4 gene impairs cell adhesion and biofilm formation in Campylobacter jejuni. in vitro. J. Med. Microbiol. 59,

(Flanagan et al., 2009) appears to bind to fibronectin and specific fibronectin binding sites have been identified in CadF (Konkel et al., 2005). The importance of CadF has been observed in a large number of strains and using a variety of different experimental approaches (Table 1). Thus, targeting the fibronectin/integrin receptor could explain why $C$. jejuni may try to reach basolateral surfaces during infection (van Alphen et al., 2008). How the bacteria breach this epithelial barrier, by a transcellular route (Figure 1D) or a paracellular route (Figure 1E), is also under much debate and not yet clear (Konkel et al., 1992b; Grant et al., 1993; Brás and Ketley, 1999; Monteville and Konkel, 2002; Hu et al., 2008; Kalischuk et al., 2009). However, the underlined importance of CadF and the fibronectin/integrin might give support to a "zipper"-like mechanism of invasion as used by Listeria or Yersinia species.

\section{CONCLUDING REMARKS}

In conclusion it is very difficult at present to conclusively state how C. jejuni facilitates its uptake into host epithelial cells. There is evidence in the literature and specifically EM images which give some support for both the "zipper" and "trigger" mechanisms of invasion, underlining the concept that $C$. jejuni enters epithelial cells by a unique novel mechanism. It may be that $C$. jejuni has developed during evolution a strategy which shares features of both of these mechanisms, but more work is clearly required to pinpoint the exact pathways used by this important pathogen to enter and survive in intestinal epithelial cells. At the moment, we favor a model where at least two major receptor-involved pathways give rise to $C$. jejuni invasion, the fibronectin/integrin, and caveolae structures (Figure 2). We also consider that caveolae and integrin may act cooperatively in GTPase signaling as shown for other cell systems (del Pozo et al., 2005; del Pozo and Schwartz, 2007). Future studies should investigate how this occurs and what are the forces triggered by the host cell that mediate engulfment, uptake, and also membrane closure behind the entering bacteria. It will be also important to investigate, in more detail, the mechanisms by which C. jejuni survives and spreads intracellularly as well as how it causes extra-intestinal infection in organs such as the liver in various animals (Hofreuter et al., 2008; Cox et al., 2009). It therefore appears that $C$. jejuni will continue to be a fascinating and rewarding research subject in the future.

\section{ACKNOWLEDGMENTS}

We thank Drs. Billy Bourke and Nicole Tegtmeyer (UCD Dublin, Ireland) for critical reading of this manuscript, and Drs. Michael Konkel (Pullman University, USA) and Jorge Galan (Yale University, USA) for providing the EM pictures in Figures 1D,E. The work of Tadhg Ó. Cróinín is supported by a research SFI grant (10/RFPgen2759) and Steffen Backert is supported through another SFI grant (UCD 09/IN.1/B2609).

FEMS Microbiol. Lett. 275, 278-285.

Ashgar, S. S., Oldfield, N. J., Woolridge, K. G., Jones, M. A., Irving, G. J., Turner, D. P., and Ala'Aldeen, D. A. (2007). CapA, an autotransporter protein of Campylobacter jejuni mediates association with human epithelial cells and colonization of the chicken gut. J. Bacteriol. 189, 1856-1865.

Bachtiar, B. M., Coloe, P. J., and Fry, B. N. (2007). Knockout mutagenesis of the KpsE gene of Campylobacter 
jejuni 81116 and its involvement in bacterium host interactions. FEMS Immunol. Med. Microbiol. 49, 149-154.

Bacon, D. J., Alm, R. A., Burr, D. H., Hu, L., Kopecko, D. J., Ewing, C. P., Trust, T. J., and Guerry, P. (2000). Involvement of a plasmid in virulence of Campylobacter jejuni 81-176. Infect. Immun. 68, 4384-4390.

Bacon, D. J., Alm, R. A., Hu, L., Hickey, T. E., Ewing, C. P., Batchelor, R. A., Trust, T. J., and Guerry, P. (2002). DNA sequence and mutational analyses of the $\mathrm{pVir}$ plasmid of Campylobacter jejuni 81-176. Infect. Immun. 70, 6242-6250.

Bacon, D. J., Szymanski, C. M., Burr, D. H., Silver, R. P., Alm, R. A., and Guerry, P. (2001). A phase-variable capsule is involved in virulence of Campylobacter jejuni 81-176. Mol. Microbiol. 40, 769-777.

Baek, K. T., Vegge, C. S., and Brondsted, L. (2011). HtrA chaperone activity contributes to host cell binding in Campylobacter jejuni. Gut Pathog. 3, 13.

Barnes, I. H., Bagnall, M. C., Browning, D. D., Thompson, S. A., Manning, G., and Newell, D. G. (2007). Gammaglutamyl transpeptidase has a role in the persistent colonization of the avian gut by Campylobacter jejuni. Microb. Pathog. 43, 198-207.

Biswas, D., Itoh, K., and Sasakawa, C. (2000). Uptake pathways of clini$\mathrm{cal}$ and healthy animal isolates of Campylobacter jejuni into INT-407 cells. FEMS Immunol. Med. Microbiol. 29, 203-211.

Biswas, D., Itoh, K., and Sasakawa, C. (2003). Role of microfilaments and microtubules in the invasion of INT407 cells by Campylobacter jejuni. Microbiol. Immunol. 47, 469-473.

Boehm, M., Krause-Gruszczynska, M., Rohde, M., Tegtmeyer, N., Takahashi, S., Oyarzabal, O. A., and Backert, S. (2012). Major host factors involved in epithelial cell invasion of Campylobacter jejuni: role of fibronectin, integrin beta1, FAK, Tiam-1, DOCK180 in activating Rho GTPase Rac1. Front. Cell. Infect. Microbiol. (in press).

Brás, A. M., and Ketley, J. M. (1999). Transcellular translocation of Campylobacter jejuni across human polarised epithelial monolayers. FEMS Microbiol. Lett. 179, 209-215.

Buelow, D. R., Christentsen, J. E., NealMcKinney, J. M., and Konkel, M. E. (2011). Campylobacter jejuni survival within human epithelial cells is enhanced by the secreted protein CiaI. Mol. Microbiol. 80, 1296-1312.
Burucoa, C., Fremaux, C., Pei, Z., Tummuru, M., Blaser, M. J., Cenatiempo, Y., and Fauchere, J. L. (1995). Nucleotide sequence and characterization of peb4A encoding an antigenic protein in Campylobacter jejuni. Res. Microbiol. 146, 467-476.

Chen, M. L., Ge, Z., Fox, J. G., and Schauer, D. B. (2006). Disruption of tight junctions and induction of proinflammatory cytokine responses in colonic epithelial cells by Campylobacter jejuni. Infect. Immun. 74, 6581-6589.

Christensen, J. E., Pacheco, S. A., and Konkel, M. E. (2009). Identification of a Campylobacter jejuni - secreted protein required for maximal invasion of host cells. Mol. Microbiol. 73, 650-662.

Cossart, P., and Sansonetti, P. J. (2004). Bacterial invasion: the paradigms of enteroinvasive pathogens. Science 304, 242-248.

Cox, N. A., Richardson, L. J., Buhr, R. J., and Fedorka-Cray, P. J. (2009). Campylobacter species occurrence within internal organs and tissues of commercial caged Leghorn laying hens. Poult. Sci. 88, 2449-2456.

De Melo, M. A., Gabbiani, G., and Pechere, J. C. (1989). Cellular events and intracellular survival of Campylobacter jejuni during infection of Hep-2 cells. Infect. Immun. 57, 2214-2222.

del Pozo, M. A., Balasubramanian, N., Alderson, N. B., Kiosses, W. B., Grande-García, A., Anderson, R. G., and Schwartz, M. A. (2005). Phospho-caveolin-1 mediates integrin-regulated membrane domain internalization. Nat. Cell Biol. 7, 901-908.

del Pozo, M. A., and Schwartz, M. A. (2007). Rac, membrane heterogeneity, caveolin and regulation of growth by integrins. Trends Cell Biol. 17, 246-250.

Desvaux, M., Hébraud, M., Henderson, I. R., and Pallen, M. J. (2006). Type III secretion: what's in a name? Trends Microbiol. 14, 157-160.

Eucker, T. P., and Konkel, M. E. (2012). The cooperative action of bacterial fibronectin-binding proteins and secreted proteins promote maximal Campylobacter jejuni invasion of host cells by stimulating membrane ruffling. Cell. Microbiol. 14, 226-238.

Fauchere, J. L., Kervella, M., Rosenau, A., Mohanna, K., and Veron, M. (1989). Adhesion to HeLa cells of Campylobacter jejuni and C. coli outer membrane components. Res. Microbiol. 140, 379-392.
Flanagan, R. C., Neal-McKinney, J. M., Dhillon, A. S., Miller, W. G., and Konkel, M. E. (2009). Examination of Campylobacter jejuni putative adhesins leads to the identification of a new protein, designated FlpA, required for chicken colonization. Infect. Immun. 77, 2399-23407.

Friedman, C. R., Neimann, J., Wegener, H. C., and Tauxe, R. V. (2000). "Epidemiology of Campylobacter jejun infections in the United States and other industrialized nations," in Campylobacter, eds I. Nachamkin and M. J. Blaser (Washington, DC: ASM Press), 121-138.

Ge, Z., Schauer, D. B., and Fox J. G. (2008). In vivo virulence properties of bacterial cytolethaldistending toxin. Cell. Microbiol. 10, 1599-1607.

Goon, S., Ewing, C. P., Lorenzo, M., Pattarini, D., Majam, G., and Guerry, P. A. (2006). sigma28-regulated nonflagella gene contributes to virulence of Campylobacter jejuni 81176. Infect. Immun. 74, 769-772.

Grant, C. C. R., Konkel, M. E., Cieplak, W. Jr., and Tompkins, L. S. (1993). Role of flagella in adherence, internalization, and translocation of Campylobacter jejuni in nonpolarized and polarized epithelial cell cultures. Infect. Immun. 61 1764-1771.

Guerry, P. (2007). Campylobacter flagella: not just for motility. Trends Microbiol. 15, 456-461.

Guerry, P., and Szymanski, C. M. (2008). Campylobacter sugars sticking out. Trends Microbiol. 16, 428-435.

Hendrixson, D. R., and DiRita, V. J. (2004). Identification of Campylobacter jejuni genes involved in commensal colonization of the chick gastrointestinal tract. Mol. Microbiol. 52, 471-484.

Hofreuter, D., Novik, V., and Galán, J. E. (2008). Metabolic diversity in Campylobacter jejuni enhances specific tissue colonization. Cell Host Microbe 4, 425-433.

Hofreuter, D., Tsai, J., Watson, R. O., Novik, V., Altman, B., Benitez, M., Clark, C., Perbost, C., Jarvie, T., Du, L., and Galán, J. E. (2006). Unique features of a highly pathogenic Campylobacter jejuni strain. Infect. Immun. 74, 4694-4707.

Hu, L., and Kopecko, D. J. (1999). Campylobacter jejuni 81-176 associates with microtubules and dynein during invasion of human intestinal cells. Infect. Immun. 67, 4171-4182.

Hu, L., and Kopecko, D. J. (2008). “Cell biology of human host cell entry by Campylobacter jejuni," in Campylobacter, eds I. Nachamkin, C. M.
Szymanski, and M. J. Blaser (Washington, DC: ASM Press), 297-313.

Hu, L., McDaniel, J. P., and Kopecko, D. J. (2006). Signal transduction events involved in human epithelial cell invasion by Campylobacter jejuni 81-176. Microb. Pathog. 40, 91-100.

Hu, L., Raybourne, R. B., and Kopecko, D. J. (2005). $\mathrm{Ca}^{2+}$ release from host intracellular stores and related signal transduction during Campylobacter jejuni 81-176 internalization into human intestinal cells. Microbiology 151, 3097-3105.

Hu, L., Tall, B. D, Curtis, S. K., and Kopecko, D. J. (2008). Enhanced microscopic definition of Campylobacter jejuni 81-176 adherence to, invasion of, translocation across, and exocytosis from polarized human intestinal Caco-2 cells. Infect. Immun. 76, 5294-5304.

Jin, S., Joe, A., Lynett, J., Hani, E. K., Sherman, P., and Chan, V. L. (2001). JlpA, a novel surface-exposed lipoprotein specific to Campylobacter jejuni, mediates adherence to host epithelial cells. Mol. Microbiol. 39, 1225-1236.

Jin, S., Song, Y. C., Emili, A., Sherman, P. M., and Chan, V. L. (2003). JlpA of Campylobacter jejuni interacts with surface-exposed heat shock protein 90 and triggers signalling pathways leading to the activation of NF-kabbaB and p38 MAP kinase in epithelial cells. Cell. Microbiol. 5, 165-174.

Kakuda, T., and DiRita, V. J. (2006). Cj1496c encodes a Campylobacter jejuni glycoprotein that influences invasion of human epithelial cells and colonization of the chick gastrointestinal tract. Infect. Immun. 74, 4715-4723.

Kale, A., Phansopa, C., Suwannachart, C., Craven, C. J., Rafferty, J. B., and Kelly, D. J. (2011). The virulence factor PEB4 (CJ0596) and the periplasmic protein Cj1289 are two structurally related SurA-like chaperones in the human pathogen Campy lobacter jejuni. J. Biol. Chem. 286, 21254-21265.

Kalischuk, L. D., Inglis, G. D., and Buret, A. G. (2009). Campylobacter jejuni induces transcellular translocation of commensal bacteria via lipid rafts. Gut Pathog. 1, 2.

Kervella, M., Pages, J. M., Pei, Z., Grollier, G., Blaser, M. J., and Fauchere, J. L. (1993). Isolation and characterisation of two Campylobacter glycineextracted proteins that bind to HeLa cell membranes. Infect. Immun. 61, 3440-3448.

Konkel, M. E., Christensen, J. E., Keech, A. M., Monteville, M. R., Klena, J. 
D., and Garvis, S. G. (2005). Identification of a fibronectin-binding domain within the Campylobacter jejuni CadF protein. Mol. Microbiol. 57, 1022-1035.

Konkel, M. E., and Cieplak, W. Jr. (1992). Altered synthetic response of Campylobacter jejuni to cocultivation with human epithelial cells is associated with enhanced internalization. Infect. Immun. 60, 4945-4949.

Konkel, M. E., Garvis, S. G., Tipton, S. L., Anderson, D. E. Jr, and Cieplak, W. Jr. (1997). Identification and molecular cloning of a gene encoding a fibronectin-binding protein (CadF) from Campylobacter jejuni. Mol. Microbiol. 24, 953-963.

Konkel, M. E., Hayes, S. F., Joens, L. A., and Cieplak, W. Jr. (1992a). Characteristics of the internalization and intracellular survival of Campylobacter jejuni in human epithelial cell cultures. Microb. Pathog. 13, 357-370.

Konkel, M. E., Mead, D. J., Hayes, S. F., and Cieplak, W. Jr. (1992b). Translocation of Campylobacter jejuni across human polarized epithelial cell monolayer cultures. J. Infect. Dis. $166,308-315$.

Konkel, M. E., and Joens, L. A. (1989). Adhesion to and invasion of Hep2 cells by Campylobacter spp. Infect. Immun. 57, 2984-2990.

Konkel, M. E., Kena, J. D., RiveraAmill, V., Monteville, M. R., Biswas, D., Raphael, B., and Mickelson, J. (2004). Secretion of virulence prtoteins from Campylobacter jejuni is dependent on a functional flagellar export apparatus. J. Bacteriol. 186, 3296-3303.

Konkel, M. E., Kim, B. J., Rivera-Amill, V., and Garvis, S. G. (1999). Bacterial secreted proteins are required for the internalization of Campylobacter jejuni into cultured mammalian cells. Mol. Microbiol. 32, 691-701.

Konkel, M. E., Larson, C. L., and Flanagan, R. C. (2010). Campylobacter jejuni FlpA binds fibronectin and is required for maximal host cell adherence. J. Bacteriol. 192, 68-76.

Konkel, M. E., Monteville, M. R., RiveraAmill, V., and Joens, L. A. (2001). The pathogenesis of Campylobacter jejuni-mediated enteritis. Curr. Issues Intest. Microbiol. 2, 55-71.

Krause-Gruszczynska, M., Boehm, M., Rohde, M., Tegtmeyer, N., Takahashi, S., Buday, L., Oyarzabal, O. A., and Backert, S. (2011). The signaling pathway of Campylobacter jejuniinduced Cdc42 activation: role of fibronectin, integrin betal, tyrosine kinases and guanine exchange factor Vav2. Cell Commun. Signal 9, 32

Krause-Gruszczynska, M., van Alphen, L. B., Oyarzabal, O. A., Alter, T., Hänel, I., Schliephake, A., König, W., van Putten, J. P., Konkel, M. E., and Backert, S. (2007a). Expression patterns and role of the CadF protein in Campylobacter jejuni and Campylobacter coli. FEMS Microbiol. Lett. 274, 9-16.

Krause-Gruszczynska, M., Rohde, M., Hartig, R., Genth, H., Schmidt, G., Keo, T., Koenig, W., Miller, W. G., Konkel, M. E., and Backert, S. (2007b). Role of the small Rho GTPases Racl and Cdc42 in host cell invasion of Campylobacter jejuni. Cell. Microbiol. 9, 2431-2444.

Lara-Tejero, M., and Galán, J. E. (2000). A bacterial toxin that controls cell cycle progression as a deoxyribonuclease I-like protein. Science 290, 354-357.

Leon-Kempis Mdel, R., Guccione, E., Mulholland, F., Williamson, M. P., and Kelly, D. J. (2006). The Campylobacter jejuni PEBla adhesin is an aspartate/glutamate-binding protein of an $\mathrm{ABC}$ transporter essential for microaerobic growth on dicarboxylic amino acids. Mol. Microbiol. 60, 1262-1275.

Lertsethtakarn, P., Ottemann, K. M., and Hendrixson, D. R. (2011). Motility and chemotaxis in Campylobacter and Helicobacter. Annu. Rev. Microbiol. 65, 389-410.

Louwen, R., Heikema, A., van Belkum, A., Ott, A., Gilbert, M., Ang, W., Endtz, H. P., Bergman, M. P., and Nieuwenhuis, E. E. (2008). The sialylated lipooligosaccharide outer core in Campylobacter jejuni is an important determinant for epithelial cell invasion. Infect. Immun. 76, 4431-4438.

MacCallum, A., Haddock, G., and Everest, P. H. (2005). Campylobacter jejuni activates mitogen-activated protein kinases in Caco- 2 cell monolayers and in vitro infected primary human colonic tissue. Microbiology 151, 2765-2772.

Malik-Kale, P., Parker, C. T., and Konkel, M. E. (2008). Culture of Campylobacter jejuni with sodium deoxycholate induces virulence gene expression. J. Bacteriol. 190, 2286-2297.

Min, T., Vedadi, M., Watson, D. C., Wasney, G. A., Munger, C., Cygler, M., Matte, A., and Young, N. M. (2009). Specificity of Campylobacter jejuni adhesin PEB3 for phosphates and structural differences among its ligand complexes. Biochemistry 48, 3057-3067.
Monteville, M. R., and Konkel, M. E. (2002). Fibronectin-facilitated invasion of T84-eukaryotic cells by Campylobacter jejuni occurs preferentially at the basolateral cell surface. Infect. Immun. 70, 6665-6671.

Monteville, M. R., Yoon, J. E., and Konkel, M. E. (2003). Maximal adherence and invasion of INT 407 cells by Campylobacter jejun requires the CadF outer-membrane protein and microfilament reorganization. Microbiology 149, 153-165.

Moser, I., Schroeder, W., and Salnikow, J. (1997). Campylobacter jejuni major outer membrane protein and a 59$\mathrm{kDa}$ protein are involved in binding to fibronectin and INT-407 cell membranes. FEMS Microbiol. Lett. 157, 233-238.

Muller, A., Leon-Kempis Mdel, R., Dodson, E., Wilson, K. S., Wilkinson, A. J., and Kelly, D. J. (2007). A bacterial virulence factor with a dual role as an adhesin and a solute binding protein: the crystal structure at $1.5 \mathrm{~A}$ resolution of the PEB1 a protein from the food borne human pathogen Campylobacter jejuni. J. Mol. Biol. 372, 160-171.

Neal-McKinney, J. M., Christensen, J. E., and Konkel, M. E. (2010). Amino-terminal residues dictate the export efficiency of the Campylobacter jejuni filament proteins via the flagellum. Mol. Microbiol. 76, 918-931.

Nothaft, H., and Szymanski, C. M. (2010). Protein glycosylation in bacteria: sweeter than ever. Nat. Rev. Microbiol. 8, 765-778.

Novik, V., Hofreuter, D., and Galan, J. E. (2009). Characterisation of a Campylobacter jejuni VirK protein homolog as a novel virulence determinant. Infect. Immun. 77, 5428-5436.

Novik, V., Hofreuter, D., and Galan, J. E. (2010). Identification of Campylobacter jejuni genes involved in its interaction with epithelial cells. Infect. Immun. 78, 3540-3553.

Oelschlaeger, T. A., Guerry, P., and Kopecko, D. J. (1993). Unusual microtubule-dependent endocytosis mechanisms triggered by Campylobacter jejuni and Citrobacter freundii. Proc. Natl. Acad. Sci. U.S.A. 90 6884-6888.

Pei, Z., Burucoa, C., Grignon, B., Baqar, S., Huang, X. Z., Kopecko, D. J., Bourgeois, A. L., Fauchere, J. L., and Blaser, M. J. (1998). Mutation in the peb1A locus of Campylobacter jejuni reduces interactions with epithelial cells and intestinal colonization of mice. Infect. Immun. 66 , 938-944.
Pei, Z. H., and Blaser, M. J. (1993). PEB1, the major cell-binding factor of Campylobacter jejuni is a homolog of the binding component in a gramnegative nutrient transport system. J. Biol. Chem. 268, 18717-18725.

Pei, Z. H., Ellison, R. T. III, and Blaser, M. J. (1991). Identification, purification and characterisation of major antigenic proteins of Campylobacter jejuni. J. Biol. Chem. 266, 16363-16396.

Poly, F., Ewing, C., Goon, S., Hickey, T. E., Rockabrand, D., Majam, G., Lee, L., Phan, J., Savarino, N. J., and Guerry, P. (2007). Heterogeneity of a Campylobacter jejuni protein that is secreted through the flagellar filament. Infect. Immun. 75, 3859-3867.

Rathbun, K. M., and Thompson, S. A. (2009). Mutation of PEB4 alters the outer membrane protein profile of Campylobacter jejuni. FEMS Microbiol. Lett. 300, 188-194.

Rivera-Amill, V., Kim, B. J., Seshu, J., and Konkel, M. E. (2001). Secretion of the virulence-associated Campylobacter invasion antigens from Campylobacter jejuni requires a stimulatory signal. J. Infect. Dis. 183, 1607-1616.

Rivera-Amill, V., and Konkel, M. E. (1999). Secretion of Campylobacter jejuni Cia proteins is contact dependent. Adv. Exp. Med. Biol. 473, 225-229.

Russell, R. G., and Blake, D. C. Jr (1994). Cell association and invasion of Caco-2 cells by Campylobacter jejuni. Infect. Immun. 62, 3773-3779.

Schröder, W., and Moser, I. (1997). Primary structure analysis and adhesion studies on the major outer membrane protein of Campylobacter jejuni. FEMS Microbiol. Lett. 150, 141-147.

Scott, N. E., Bogema, D. R., Connolly, A. M., Falconer, L., Djordjevic, S. P., and Cordwell, S. J. (2009). Mass spectrometric characterization of the surface expressed $42 \mathrm{kDa}$ lipoprotein $\mathrm{JlpA}$ as a glycosylated antigen in strains of Campylobacter jejuni. J. Proteome Res. 8, 4654-4664.

Scott, N. E., Marzook, N. B., Deutscher, A., Falconer, L., Crossett, B., Djordjevic, S. P., and Cordwell, S. J. (2010). Mass spectrometric characterization of the Campylobacter jejuni adherence factor CadF reveals post-translational processing that removes immunogenicity while retaining fibronectin binding. Proteomics 10, 277-288.

Song, Y. C., Jin, S., Louie, H., Ng, D., Lau, R., Zhang, Y., Weerasekera, R., Al Rashid, S., Ward, L. A., Der, S. D., and 
Chan, V. L. (2004). FlaC, a protein of Campylobacter jejuni TGH9011 (ATCC43431) secreted through the flagellar apparatus, binds epithelial cells and influences cell invasion. Mol. Microbiol. 53, 541-553.

Szymanski, C. M., Burr, D. H., and Guerry, P. (2002). Campylobacter protein glycosylation affects host cell interactions. Infect. Immun. 70, 2242-2244.

Szymanski, C. M., King, M., Haardt, M., and Armstrong, G. D. (1995). Campylobacter jejuni motility and invasion of Caco-2 cells. Infect. Immun. 63, 4295-4300.

Tegtmeyer, N., Rohde, M., and Backert, S. (2011). "Clinical presentations and pathogenicity mechanisms of bacterial foodborne infections," in Microbial Food Safety: An Introduction, eds O. A. Oyarzabal and S. Backert (New York: Springer), 13-31.

Tu, Q. V., McGuckin, M. A., and Mendz, G. L. (2008). Campylobacter jejuni response to human mucin MUC2: modulation of colonization and pathogenicity determinants. $J$. Med. Microbiol. 57, 795-802.

van Alphen, L. B., Bleumink-Pluym, N. M., Rochat, K. D., van Balkom, B. W., Wösten, M. M., and van Putten, J. P. (2008). Active migration into the subcellular space precedes Campylobacter jejuni invasion of epithelial cells. Cell. Microbiol. 10, 53-66.

van Spreeuwel, J. P., Duursma, G. C. Meijer, C. J., Bax, R., Rosekrans, P. C., and Lindeman, J. (1985). Campylobacter colitis: histological immunohistochemical and ultrastructural findings. Gut 26, 945-951.

Watson, R. O., and Galán, J. E. (2008). Campylobacter jejuni survives within epithelial cells by avoiding delivery to lysosomes. PLoS Pathog. 4, e14. doi:10.1371/journal.ppat.0040014

Watson, R. O., Novik, V., Hofreuter, D., Lara-Tejero, M., and Galán, J. E. (2007). A MyD88-deficient mouse model reveals a role for Nramp1 in Campylobacter jejuni infection. Infect. Immun. 75, 1994-2003.
Wooldridge, K. G., Williams, P. H., and Ketley, J. M. (1996). Host signal transduction and endocytosis of Campylobacter jejuni. Microb. Pathog. 21, 299-305.

Yao, R., Burr, D. H., Doig, P., Trust, T. J. Niu, H., and Guerry, P. (1994). Isolation of motile and non-motile insertional mutants of Campylobacter jejuni: the role of motility in adherence and invasion of eukaryotic cells. Mol. Microbiol. 14, 883-893.

Young, G. M., Schmiel, D. H., and Miller, V. L. (1999). A new pathway for the secretion of virulence factors by bacteria: the flagellar export apparatus functions as a protein-secretion system. Proc. Natl. Acad. Sci. U.S.A. 96, 6456-6461.

Young, K. T., Davis, L. M., and Dirita, V. J. (2007). Campylobacter jejuni: molecular biology and pathogenesis. Nat. Rev. Microbiol. 5, 665-679.

Ziprin, R. L., Young, C. R., Stanker, L. H., Hume, M. E., and Konkel, M. E. (1999). The absence of cecal colonization of chicks by a mutant of Campylobacter jejuni not expressing bacterial fibronectinbinding protein. Avian Dis. 43, 586-589.

Conflict of Interest Statement: The authors declare that the research was conducted in the absence of any commercial or financial relationships that could be construed as a potential conflict of interest.

Received: 01 November 2011; accepted: 17 February 2012; published online: 05 March 2012

Citation: Ó Cróinín $T$ and Backert $S$ (2012) Host epithelial cell invasion by Campylobacter jejuni: trigger or zipper mechanism? Front. Cell. Inf. Microbio. 2:25. doi: $10.3389 /$ fcimb.2012.00025 Copyright (c) 2012 O Cróinín and Backert. This is an open-access article distributed under the terms of the Creative Commons Attribution Non Com mercial License, which permits noncommercial use, distribution, and reproduction in other forums, provided the original authors and source are credited. 